\title{
CONSUMO E PRODUÇÃo DE SUBJETIVIDAdE NAS TVS COMUNITÁRIAS
}

\author{
Luciana Lobo Miranda
}

\begin{abstract}
RESUMO
Este artigo discute a produção de subjetividade em duas TVs comunitárias: TV Maxambomba e TV Pinel. Mediante uma pesquisa qualitativa, buscou-se analisar os processos subjetivos engendrados em jovens da periferia ou usuários do sistema de saúde mental quando eles passam de simples espectadores a criadores de produtos audiovisuais. Procurou-se enfatizar diferenças e semelhanças entre a $T V$ de massa e as TVs comunitárias. Pôde-se com isso perceber a apropriação de signos da TV de massa na programação das TVs comunitárias, bem como a diferenciação no processo de produção e de consumo na relação com o espectador.

Palavras-chave: Subjetividade. TV Comunitária. Consumo.

\section{CONSUMPTION AND THE PRODUCTION OF SUBJECTIVITY IN COMMUNITARIAN TELEVISION}

Abstract

The present article discusses the production of subjectivity in two communitarian TV networks: TV Maxambomba and TV Pinel. Based on a qualitative research, we analyzed the subjective processes that took place in youngsters from peripheric areas or users of the mental health system when they stop being just spectators and begin to create audiovisual products. Special emphasis was given to the differences and resemblances between mass television and communitarian television. Therefore we could notice the appropriation of mass television signs in the communitarian TV networks as well as the difference in the process of production and consumption regarding the spectators.
\end{abstract}

Keywords: Subjectivity. Communitarian TV. Consumption.

\footnotetext{
* Doutora em Psicologia pela PUC - RJ, Professora Adjunta do Departamento de Psicologia da Universidade Federal do Ceará.

Endereço: Rua Professor Dias da Rocha 490/ Apto. 202, Fortaleza. Cep: 60170-310

E-mail:1obo.lu@uol.com.br
} 
A experiência do homem contemporâneo encontra-se cada vez mais mediada pelos meios de comunicação de massa, com destaque para a televisão. Ao contrário do computador, a televisão cobre praticamente $100 \%$ do território nacional, difundindo valores, costumes e comportamentos.

O barateamento dos aparelhos tecnológicos, principalmente a TV, foi um dos responsáveis pela democratização da informação. No Brasil, é cada vez maior o número de aparelhos de TV nas chamadas classes populares. A televisão representa hoje um importante acesso aos bens culturais e de entretenimento, gerando muitas vezes a massificação de gostos, desejos, costumes, valores e modos de pensar. A tela de TV aparece como a nova janela para o mundo. Os fatos ganham maior credibilidade quando são mediados pelos sistemas de informação/comunicação. Nesta relação de alteridade contemporânea, muitas vezes o "outro" é a imagem da TV, com a qual o sujeito dialoga, concorda ou não, reconhece-se ou não.

Como conseqüência do barateamento da tecnologia da imagem, nos anos 1980, temos o surgimento das TVs de rua/comunitárias no Brasil, tendo a TV Maxambomba como uma de suas pioneiras. Na década de 90 , sob a assessoria da TV Maxambomba, é criada a TV Pinel, sustentando a bandeira do Movimento Nacional da Luta Antimanicomial ${ }^{1}$. Entretanto, a questão central na realização de experiências do tipo que vamos aqui analisar não é apenas o uso da linguagem audiovisual de um aparato tecnológico para discussão de temas relevantes, mas a própria discussão dessa mesma linguagem e de sua apropriação na reflexão da vida e do mundo das pessoas envolvidas.

Bucci (2002) ao comentar o sexto aniversário da TV Pinel, em reportagem publicada no suplemento de TV da Folha de São Paulo, diz ser esta TV uma "ilha ética" em meio ao mar midiático, onde as leis do consumo e do mercado imperam sobre a dignidade da pessoa. $\mathrm{O}$ articulista é contundente: não é um programa isolado, mas o que está em jogo é uma lógica perversa da TV comercial como um todo:

A televisão revelou, [...], o avesso da civilização: se a civilização seria a vitória da convivência pacífica sobre a selva, ela descortina a inviabilidade da convivência porque se tornou um veículo incapaz de pôr o respeito à pessoa acima dos imperativos do mercado e do consumo. (BUCCI, 2002, p. 2)

No contrafluxo dessa lógica, a TV Pinel, feita por usuários do sistema de saúde mental, no Instituto Philippe Pinel (IPP-RJ) chamaria atenção não pelo resultado estético, mas por sua ética de respeito à pessoa, que, quando em surto, não é filmada, pois não pode ser responsabilizada pelos seus atos. Na TV Pinel, não há a camisa de força do ibope, do mercado, da publicidade para ditar a produção. $\mathrm{O}$ tempo também não é o industrial, imposto pela produtividade em série, mas criase e re-cria-se no tempo comunal, isto é, no tempo dos usuários, técnicos, funcionários, corpo médico que, mesmo com responsabilidade e um cronograma a cumprir, deve ser respeitado. 
Esta mesma apreciação pode se estender ao Projeto: "Capacitação de Jovens em Produção de Vídeo" da TV Maxambomba, que junto com a TV Pinel fizeram parte da presente pesquisa. A TV Maxambomba feita por jovens de Rancho Fundo, periferia de Nova Iguaçu, Baixada Fluminense-RJ, pretende afirmar a existência na região para além da violência e miséria, quando, via de regra, suas imagens encontram-se associadas.

A nosso ver, tais projetos podem ser considerados experiências em TV comunitária, e têm como traços comuns, não só o fato de trazer a marca da proximidade imagem-espectador, partindo de temas considerados de interesse para a comunidade, mas também por possibilitar a apropriação da linguagem imagética, em seu processo de criação, pelos membros da comunidade. Tanto os jovens, como os usuários do sistema de saúde mental não são mais representados em suas idéias, mas são eles mesmos que protagonizam esta narrativa contemporânea, o vídeo, para falar de seu cotidiano, de suas vidas.

Assim, o vínculo comunitário não se confunde com segmentação do público, determinada por uma temática, no caso loucura ou juventude, nem com prestação de serviço, com notícias e informações de interesse da região, bairro, ou da instituição atendida. O que faz desses projetos, experiências em TVs comunitárias, é a relação que mantêm com as comunidades onde estão inseridas, sendo pensadas e elaboradas desde a pauta à exibição, passando pelo roteiro, filmagem e edição, pelos seus membros, em parceria com a equipe.

Ao longo da pesquisa trabalhamos a produção de subjetividade nessas experiências, tendo como eixo temático central, não a questão psiquiátrica da TV Pinel, nem uma análise sociológica sobre jovens nas periferias de grandes centros urbanos, embora ambas estejam presentes, mas o que se coloca no foco de nosso interesse é o processo de realização de vídeos, numa vertente comunitária.

Nossa pesquisa objetivou analisar a produção de subjetividade engendrada pela experiência de criação de vídeos comunitários, realizados na TV Pinel e no projeto "Capacitação de Jovens em Produção de Vídeo" da TV Maxambomba, em que deixam de ser apenas enunciados nos discursos/imagens de outros, seja em programas de TV de massa, comerciais ou educativos, e passam a ser protagonistas desta narrativa contemporânea, enunciando-se a si mesmos.

Em termos teórico-metodológicos, nossa análise orientou-se para a intertextualidade dos discursos. Baseado na filosofia da linguagem de Mikhail Bakhtin (1992, 1995), procuramos constituir um campo discursivo dialógico marcado pela relação de alteridade pesquisador e seu "outro", isto é, o interlocutor do pesquisador, aquele "a quem" ele se dirige em situação de campo e "de quem" ele fala em seu texto (AMORIM, 2001). Se o mais importante eram os afetos, as formas sensíveis, os discursos, os valores, enfim a subjetividade produzida na experiência dessas TVs, tornou-se valioso ter inúmeras entradas quanto possíveis, visando ao acompanhamento de seus trabalhos, que compreendeu a linguagem oral dos sujeitos envolvidos, (observação e entrevistas), a produção escrita (projetos e relatórios), e a linguagem audiovisual (os vídeos). Cada entrada teve sua especificidade e sua importância. A freqüência da ida a campo, entre os anos de 
1999 e 2002, variou entre uma e duas vezes por semana, com duração de aproximadamente 3 horas, dependendo do momento de produção do projeto. No presente trabalho apresentaremos trechos dos depoimentos de alguns jovens e usuários, a partir das entrevistas gravadas em fitas cassete ou vídeo VHS.

\title{
ProduÇão de SUbJeTIVIDAde E TVS COMUNitÁRIAS: UM ESTUdo POSSíVEL
}

Faz-se necessário a definição, mesmo que de forma sucinta, do que estamos chamando de produção de subjetividade. ${ }^{2}$ Ao invés de encontrar-se localizada numa substancialidade psíquica, como é comumente tratada no discurso "psi", propomos, com auxílio do pensador Félix Guattari um redimensionamento deste conceito, onde, segundo o autor, a subjetividade encontra-se constantemente produzida por “...instâncias individuais, coletivas e institucionais" (GUATTARI, 1992, p. 11), sem que haja qualquer hierarquia entre elas. Subjetividade para além do sujeito individual, produzida junto ao socius.

Deleuze e Guattari, em o Anti-Édipo (1972), situam a psicanálise, agenciada aos equipamentos coletivos de dominação, como uma das responsáveis pela individualização da subjetividade, ao reduzir as relações de alteridade ao núcleo familiar, seja ele consanguíneo, seja por derivações simbólicas. Grosso modo, a prática da psicanálise acabou por reduzir os fatos sociais a mecanismos puramente psicológicos. O que estes pensadores evocam é a não limitação do desejo à cena familiar, e a compreensão de que o romance familiar depende dos investimentos sociais, e não o contrário.

Por outro lado, em Caosmose (1992) Guattari discute o inconsciente freudiano como de grande importância para a compreensão da subjetividade contemporânea. Tal descoberta, ou como prefere localizar, invenção, devidamente datada, funcionou como uma incrível máquina que abalou a medicina mental tradicional da virada do séc. XIX. Ainda hoje, segundo o autor, cabe à psicanálise escapar das modelizações adaptativas e agenciar-se as singularizações de nossa época.

Nesta obra, o autor problematiza o conceito de subjetividade a fim de "[...] ultrapassar a oposição clássica entre sujeito individual e sociedade [...]" (GUATTARI, 1992, p. 11). No capítulo intitulado "Da Produção de Subjetividade" Guattari enfatiza sua opção em não mais trabalhar com a noção de sujeito, pois a considera já impregnada de um psiquismo individualizante e substancializado, impossibilitando a articulação de instâncias coletivas, seja de ordem política, social ou econômica:

\begin{abstract}
Proporemos então operar um descentramento da questão do sujeito para a da subjetividade. O sujeito, tradicionalmente, foi concebido como essência última da individualização, como pura apreensão pré-reflexiva, vazia, do mundo, como foco da sensibilidade, da expressividade, unificador dos estados de consciência. Com a subjetividade, será dada, antes, ênfase à instância fundadora da intencionalidade. "Trata-se de tomar a relação entre o sujeito e o objeto pelo meio"[...]. (GUATTARI, 1992, p. 35)
\end{abstract}


O autor discute a subjetividade não como uma substância essencial do sujeito, mas sob a ótica da produção: componentes de subjetivação (1990) ou produção de subjetividade (1992) seja ela de instâncias individuais, coletivas ou institucionais:

Considerar a subjetividade sob o ângulo da sua produção não implica absolutamente, a meu ver, voltar aos sistemas tradicionais de determinação do tipo infra-estrutura material - superestrutura ideológica. Os diferentes registros semióticos que concorrem para o engendramento da subjetividade não mantêm relações hierárquicas obrigatórias, fixadas definitivamente [...] "A subjetividade, de fato, é plural, "polifônica", para retomar uma expressão de Mikhail Bakhtine e ela não conhece nenhuma instância dominante de determinação que guie as outras instâncias segundo uma causalidade unívoca. (GUATTARI, 1992, p. 11)

Guattari, ao utilizar-se deste conceito bakhtiniano, pretendeu enfatizar o caráter heterogêneo e social da subjetividade enquanto Agenciamentos Coletivos de Enunciação, que compreendem tanto o sujeito da enunciação (sujeito que narra), como o do enunciado (sujeito que diz ou faz) que podem se confundir numa só voz, onde uma fala não é necessariamente produzida por um só sujeito, mas pode lhe ser anterior e coletiva. Na voz de um sujeito, ecoam inúmeras vozes: sujeito produtor e produto de vetores de subjetivação ${ }^{3}$.

Dessa forma, as mudanças no campo da tecnologia, as relações espaçotemporais, a produção de imagens, para apenas citar alguns exemplos, são fundamentais para o entendimento dos caminhos da produção da subjetividade contemporânea:

Seria conveniente definir de outro modo à noção de subjetividade renunciando totalmente à idéia de que a sociedade, os fenômenos de expressão social são a resultante de um simples aglomerado, de uma simples somatória de subjetividades individuais. Penso, ao contrário, que é a subjetividade individual que resulta de um entrecruzamento de determinações coletivas de várias espécies, não só sociais, mas econômicas, tecnológicas, de mídia, etc. (GUATTARI; ROLNIK, 1986, p. 34)

Segundo Guattari e Rolnik (1986) é o desenvolvimento do capitalismo que traz a marca da individualidade na subjetividade, conforme a entendemos atualmente. O sistema capitalista tende a criar padrões universais, ao mesmo tempo que individualiza tais padrões. Se atualmente reconhecemos a subjetividade em seu modelo personológico, muitas vezes atrelada ao consumo, é porque temos, com o avanço do capitalismo, uma subjetividade confinada à individualidade:

Essa cultura de massa produz, exatamente, indivíduos: indivíduos normalizados, articulados uns aos outros, segundo sistemas hierárquicos, sistemas de valores, sistemas de 
submissão. [...] Não somente uma produção de subjetividade individuada - subjetividade dos indivíduos - mas uma produção de subjetividade social, uma produção da subjetividade que se pode encontrar em todos os níveis da produção e do consumo. E mais ainda: uma produção da subjetividade inconsciente. A meu ver, essa grande fábrica, essa grande máquina capitalística produz inclusive aquilo que acontece conosco quando sonhamos, quando devaneamos, quando fantasiamos, quando nos apaixonamos e assim por diante. Em todo caso, ela pretende garantir uma função hegemônica em todos os campos. (GUATTARI; ROLNIK, 1986, p. 16)

Poder-se-ia então pensar que o aparecimento da TV Maxambomba e da TV Pinel pertencem ao processo de individualização e de personalização da subjetividade, onde todos podem e devem se expressar? Seria esta forma de fazer TV apenas um mero canal de expressão de jovens ou de usuários do sistema de saúde mental na cultura de massa, que apenas revelaria o prazer narcísico de se ver na telinha, atuando como uma nova marca a ser consumida? $\mathrm{Ou}$, ao contrário, tais trabalhos assumiriam um lugar de questionamento da experiência de ver e de produzir imagens técnicas? O fato de se apropriarem de uma linguagem já conhecida, para fazer falar o jovem do subúrbio ou o louco, produziria um campo de resistência? Como se dá à produção de subjetividade na TV comunitária, visto que os sujeitos que criam e/ou assistem a esta programação são também consumidores das imagens da mídia comercial? São várias as questões que serviram de guia para a nossa reflexão, na busca da análise da especificidade da TV comunitária e de seus protagonistas, articulada ao universo da grande mídia televisiva.

Assim, ao longo do processo da pesquisa, ao analisar a produção de subjetividade da TV Pinel e do projeto "Capacitação de Jovens na Produção de Vídeo" da TV Maxambomba, alguns temas mostraram-se relevantes, dentre os quais, destacaremos neste trabalho as diferenças e semelhanças entre TV de massa e estas experiências em TV comunitária, no nível de produção e de consumo.

\section{TV MAXAMBOMBA "O QUE VOCÊ VÊ NO TELÃO, VOCÊ NÃO VÊ NA TELINHA".}

\section{TV PINEL "POR UMA NOVA IMAGEM DA LOUCURA" 4}

A TV Maxambomba, ligada ao CECIP, Centro de Criação da Imagem Popular, foi uma TV de rua/comunitária pioneira no Brasil, surgindo em 1986, em Rancho Fundo, periferia de Nova Iguaçu, gravando e exibindo seus programas nas praças da região. Nos anos seguintes, enfrentando vicissitudes, ela reformulou sua ação militante ligada aos movimentos populares, sobretudo às comunidades eclesiais de base, para o trabalho com a comunidade, no sentido mais amplo: a comunidade de moradores, principalmente jovens, passando a investir em sua formação para que eles conduzissem o seu próprio discurso, através de vídeos criados por eles mesmos, chegando assim, a partir de 1999, ao projeto "Capacitação 
de Jovens em Produção de Vídeo", que trabalhou com jovens entre 12 e 18 anos, acompanhado de perto pela presente pesquisa.

Neste projeto, três jovens entre 17 e 19 anos, antigos "Repórter de Bairro", com atuação na TV desde os seus 14 anos, assumiram a monitoria dos grupos de trabalho para a realização dos vídeos comunitários ${ }^{5}$. A equipe e os monitores atuaram na formação de jovens alunos na produção de vídeos comunitários em cursos com duração que variaram entre 3 e 6 meses. No processo de criação destes vídeos, os alunos escolheram os temas, assinaram roteiros, produziram, filmaram, dirigiram, editaram, fizeram créditos, vinhetas, etc.

Além da parte teórica de linguagem e técnica de vídeo, houve discussões sobre o uso da mídia, o poder da imagem, cidadania, Estatuto da Criança e do Adolescente (ECA) bem como um estágio para os alunos em diferentes TVs (TVE, Canal Futura, TVPinel e TVFacha) ${ }^{6}$, e a exibição dos vídeos produzidos pelos alunos na praça da região, com discussão em "câmera aberta"7.

Em 1996, com uma assessoria dada pela TV Maxambomba, a TV Pinel passa a funcionar dentro de uma instituição psiquiátrica, o Instituto Philippe Pinel, IPP, em Botafogo, Zona Sul do Rio de Janeiro, onde também ocorre a exibição de seus programas. Os laços entre estas duas TVs comunitárias se estreitam e vários antigos "Repórter de Bairro" ou integrantes do CECIP passam a integrar a TV Pinel.

Tendo o engajamento na luta antimanicomial como sua marca específica, esta TV vem produzindo seus programas com funcionários e usuários do IPP, sendo que alguns destes últimos, fazendo parte efetiva da equipe, são por isso remunerados. $\mathrm{O}$ formato é de uma revista televisiva, com uma linguagem própria, onde alternam quadros de humor e paródia, a reportagens sobre a luta antimanicomial, entrecortadas por vinhetas. Já no primeiro programa, em abril de 1996, a TV Pinel ironicamente pergunta: “TV Pinel? Qual é o canal?”.

Os programas têm uma periodicidade trimestral (interrompida em períodos de dificuldade financeira), e a exibição se dá no auditório da instituição. A TV Pinel promove, em média, duas vezes por ano, exibições em praça pública. Esta TV também tem seus programas veiculados no canal comunitário da Net-Rio e Canal Saúde, programa exibido pela TVE, além de freqüentemente ser objeto de reportagem da grande mídia (Canal Futura, TVE e Rede Globo, além da mídia impressa).

As duas TVs constituíram-se num instigante desafio: falar de TV comunitária, feita por jovens moradores de periferia do Rio de Janeiro e por usuários do sistema de saúde mental, num país marcado pelo monopólio da comunicação. Ambas nascem com anseios comuns: colocar em discussão a democratização dos meios de comunicação, ao mesmo tempo buscar reverter à exclusão em que vivem em seu cotidiano. Os estereótipos divulgados pela mídia da figura do louco vista em geral como perigosa e da juventude na Baixada, associada à miséria, drogas e violência, passam a ser fortemente questionados.

Porém, ao invés de se colocarem à margem dessa mesma mídia, buscam capturar este meio, dando visibilidade a outras formas de existência da loucura e 
da Juventude na Baixada, possibilitando que jovens e usuários falem do seu cotidiano, pelos vídeos produzidos por eles mesmos, conquistando assim uma outra dimensão das questões sociais, políticas e culturais do contexto em que vivem. Examinemos como exemplo os slogans de ambas, propositalmente destacados no sub-título do presente artigo.

Baudrillard (1995) recorrendo ao campo da linguagem, explica a lógica do consumo segundo a manipulação de significantes sociais. Não se consome o objeto em si, mas o que ele representa (conforto, status, etc.) onde um signo se liga a outro, constituindo o valor-signo. Desta forma, qualquer objeto pode ser substituído por outro, contanto que exerça a mesma função. O objeto, ao assumir o lugar de signo, deixa de estar ligado ao binômio necessidade/satisfação, relacionado à finalidade racional do objeto, para entrar na ordem do desejo, fundado na carência, campo móvel e inconsciente de significação, que se ressignifica localmente nestes mesmos objetos. "Se se admitir antes que a necessidade nunca é tanto a necessidade de tal objeto quanto a "necessidade" de diferença ("o desejo" do sentido social) compreender-se-á então porque é que nunca existe satisfação "completa", nem "definição" de necessidade" (BAUDRILLARD, 1995, p. 78). Dentre os inúmeros recursos de persuasão da publicidade na atualização da "necessidade da diferença" está o Slogan.

Slogans, tão comum em campanhas publicitárias, onde palavras, frases e enunciados em seu valor-signo nos lembram a todo instante que só existimos para consumir, são apropriados em sua lógica para chamar atenção do espectador para um outro possível, onde a referência é a TV de massa. A TV Maxambomba convida o espectador a ter uma nova experiência com a TV: "O que você vê no telão, você não vê na telinha", instigando a curiosidade do telespectador, estabelecendo uma comparação para uma outra forma de fazer TV, diferente do que vê cotidianamente na privacidade do lar. A TV Pinel também estabelece uma comparação com a TV diária. Eles desejam uma "outra" imagem, inabitual, já que é a TV que vincula "a" imagem da loucura carregada de estereótipos, na qual pretendem reverter.

Existem diferenças entre os dois projetos: um, no interior de um hospital psiquiátrico, tendo a luta antimanicomial como bandeira; outro, apostando nas possibilidades sócio-culturais da juventude na periferia de um grande centro urbano. Mas foi possível aproximá-los sob a égide da exclusão e da democratização da comunicação, bem como do ponto de vista metodológico. Ambos buscam uma metodologia participativa - "o vídeo-processo" - onde o fazer vídeo comunitário se dá como uma produção coletiva, no limite, não autoral, onde a equipe da TV se mistura com a comunidade envolvida para criar pautas, escrever roteiros, fazer produção, operar a câmera, $\operatorname{gravar}^{8}$... As exibições são também coletivas, nos auditórios e praças públicas. Cria-se uma expectativa. O carro de som anuncia a programação, filipetas e cartazes são distribuídos. Ademais, o trocar idéias, trabalhar para além de qualquer terapia ocupacional, descobrir belezas tão próximas e escondidas, deslocar-se em lugares desconhecidos e inesperados (seja da mente humana, seja da natureza), é tão importante quanto dominar a linguagem técnica do vídeo. 


\section{Atratore estranhos: A RElaÇ̃̃o tV de massa e tV COMUnitária}

Tanto o projeto de "Capacitação de Jovens em produção de vídeo" da TV Maxambomba, como a TV Pinel nascem de um compromisso de produzir, através da linguagem da TV, relações menos estereotipadas, seja com relação aos moradores da Baixada, seja com relação à loucura. Isto se evidencia quando, por exemplo, os jovens da Maxambomba relatam que normalmente a televisão só dá visibilidade à região quando se trata de violência e miséria. A crítica às formas de abordagem do jovem, da Baixada e da loucura feitas pela TV de massa, encontra-se presente em seus depoimentos. Vejamos o que dizem os Jovens da Maxambomba em alguns trechos das entrevistas gravadas :

B - Se acontecer um roubo aqui, um desastre eles [os jornalistas] vêm correndo. É igual urubu. Tem uma carne seca aí, um troço podre, eles vêm em cima, eles só querem troço podre!

D - Baixada eles nem olham....

L - Quando vem Prefeito, Deputado, para vir falar que construiu, asfaltou estrada aqui e ali. Só para isso, só para benefício próprio, eles [os jornalistas] só falam em benefício próprio.

Estes jovens também criticam o tratamento dado aos programas da TV de massa voltados à juventude:

D - Eles acham que os jovens só servem para gastar dinheiro, para namorar, para ir para o shopping, para ter aquele grupinho conversando. Não pensa que o jovem pobre precisa de um estudo, precisa de um trabalho. Agora eles não, os jovens da televisão já tem tudo, o dia todo.

P - A própria Malhação...

G- Agora P. , você me diz, da outra vez que a gente estava tendo um debate na sala. Nós estávamos falando que eu gostava de programa de televisão. As pessoas falaram assim: 'só aparece fulano para cima e para cá, fulano indo para o shopping, ninguém fala em estudar!' E agora, na nova fase de Malhação? Está tendo programa nas escolas!

D- Mas não é da maneira da gente. É da maneira deles, maneira dos ricos. Eles não põem pobre ali, por que não? [...]. Pois se tu vê ali na Malhação a escola não tem nada a ver, escola daquele jeito!

$\mathrm{P}$ - Eu não pareço com nada disso!

L - Eles mostram outro tipo de jovem.

D - Eles acham que a gente é ladrão, é analfabeto, não serve para nada, a gente com 17 anos para arrumar um emprego é um sacrifício [...] O rico não, com 17 está lá trabalhando com o papai, enquanto a gente luta por aquele trabalho. Tem jovem com 16 anos que está trabalhando em casa de família, lavando 
roupa, enquanto o rico está lá, sentado com os coleguinhas, indo para o shopping. Eu não, apesar de que eu gosto. Vai dizer que você não gosta de ir para um shopping de dia? Mas se eu pudesse... [...] A gente tem que lutar por aquilo, para arrumar um dinheiro para ir para o shopping, tem que suar para ganhar $\mathrm{R} \$ 10,00 .$.

G- Eu não ligo se eles criticam ou não criticam...

Apesar das opiniões não serem consensuais, visto que a aluna "G" defende os programas voltados para a sua idade, os outros jovens são claros ao evidenciar a ineficácia da TV de massa como um vídeo-espelho. A aluna "P" comenta: "Eu não pareço com nada disso". A TV, ao estipular um padrão médio, naturaliza a juventude, retirando-a do contexto de sua experiência histórica, cultural e econômica. Respaldada em ideais burgueses, ela exclui o cotidiano desglamourizado destes jovens moradores da Baixada, e que, talvez por isso mesmo, não mereça ser registrado. Por outro lado, estes jovens também idealizam a "vida de rico" homogeneizado numa existência única, isto é, os ricos vivem para comprar. "D" critica a forma de ser dos ricos, mas revela que, no campo desejante, também participa dos mesmos códigos do consumo: "apesar de que eu gosto. Vai dizer que você não gosta de ir para um shopping de dia? mas se eu pudesse..."

A TV Pinel, como se viu, nasce com o objetivo de mudar a imagem que se tem da loucura. A maneira como a doença mental é tratada na grande mídia, próxima à periculosidade ou à invalidez, parece incomodar:

E- É o seguinte, a tevê estereotipa o louco. O louco geralmente aparece como improdutivo, como aquele cara que tem uma característica que todo mundo percebe. [...] Eu por exemplo, eu passo também por aqui, eu sou usuário. Eu posso aparecer normalmente na televisão, mas não como eles mostram em novela, em reportagens que fazem. O louco quase não fala, geralmente quando fala é pra ser motivo de chacota, engraçado, algum tipo estereotipado ou então internado, jogado em manicômios, asilados, essas coisas assim.

No entanto, a recusa de como são representados na TV de massa, não implica necessariamente numa negação absoluta de seu padrão. Destaquemos, por exemplo, a maneira como a TV de massa, e mais especificamente, a TV comercial se faz presente nesses projetos, tanto na forma, priorizando gêneros consagrados na grande TV, como o telejornalismo, a novela e a publicidade, quanto no conteúdo, discutindo temas expostos na mídia.

$\mathrm{Na}$ TV Maxambomba alguns vídeos produzidos pelos jovens, para serem exibidos nas praças públicas foram o vídeo-reportagem "Cães Ferozes" que refletiu a polêmica sobre os cachorros da raça "pit-bulls" dos noticiários da época; o "Pagodeando", pequena ficção sobre um grupo de pagode da região, sendo que o pagode é um dos "gêneros musicais" com maior espaço na grande mídia e na indústria fonográfica brasileira; o gênero ficção como uma pequena novelinha também é explorado no vídeo "Violência pra quê? e no Sexo Protegido, Vida 
Garantida". Em termos de recursos técnicos audio-visuais, podemos citar o uso do strob, que faz a imagem parecer quase quadro a quadro, bastante utilizado em vídeo-clips veiculados da MTV e explorado na abertura do Vídeo "Cultura e Lazer" em Tinguá, ao som de um rock.

Na TV Pinel, "A Indomada", novela das 8 da Rede Globo, vira "A Endoidada" (agosto de 1997); os meninos DDD do comercial da Embratel se transformam em IPP (Instituto Philippe Pinel) (maio de 1999); a sonoridade sibilante do tssss, do comercial de cerveja, é parodiado numa pseudo-propaganda Haldol, medicação muito utilizada por pacientes psiquiátricos (agosto de 1999). Enfim, elementos da mídia televisiva comercial são utilizados de forma muito bemhumorada para falar sobre o cotidiano da doença mental, nos casos citados, pelo uso da paródia.

A TV de massa faz parte da formação visual tanto dos membros da equipe técnica como dos jovens e usuários. O cotidiano dos jovens da Maxambomba e dos usuários do IPP encontra-se inevitavelmente atravessado pelas imagens da mídia convencional. Este "outro", imagem/discurso da TV de massa, que, às vezes, eles procuram repelir, mas que de modo ambivalente os fascina, está presente e é reproduzido em suas vozes/imagens.

Vejamos por exemplo os depoimentos na TV Maxambomba acerca do que teria motivado alguns desses jovens a se inscrever nos cursos oferecidos por esta TV:

$\mathrm{V}$ - Eu tinha uma curiosidade imensa prá saber como se gravava, né? como se fazia reportagem, enfim... desde criança que eu via os programas e queria saber como são os bastidores, ter uma noção, aí foi isso que me levou a fazer o curso.

B-[Referindo-se a TV Maxambomba] È um modo diferente de trabalhar em TV. Coisa que é muito difícil de você encontrar oportunidade de trabalhar em TV. Então, eu pensei assim: "poxa, já trabalhando assim, não custa nada, desde novo começar na TV, assim, devagar. Chegar de repente, fazer uma faculdade e querer entrar logo numa TV... nunca ia dar certo. Aí eu pensei assim: "eu vou começar com um cursinho"...

Ao final do curso, o desejo de seguir carreira na televisão seja como câmera, roteirista, ou ator, é quase uma unanimidade. Mesmo não tendo como fim último, a profissionalização desses jovens, para muitos deles, a "oportunidade" de fazer um curso oferecido pela TV Maxambomba, representa um degrau a mais no sonho de seguir uma carreira dentro de uma grande TV. TV Pinel:

A mitificação com relação à TV de massa encontra-se também presente na

M- Você pode perceber que eles [atores da Globo] são tudo, né? Aí, você fala assim: Pô, aquele cara foi produzido pelo estúdio. Que nada, o cara tá se cuidando porque ele preserva a imagem dele. Esse é o processo natural do vídeo mesmo. O cara cuidar da imagem, o cara, não: pô , peraí. Peraí, vai me entrevistar. "Peraí que eu vou dar uma penteada no cabelo"! 
Coube-nos então o seguinte questionamento: em que medida o entendimento da linguagem televisiva no interior dessas experiências em TV Comunitária servem para a desmistificação da TV de massa, ao contrário, reforça o próprio mito? Poderse-ia supor que os discursos desses jovens ou usuários, a curiosidade de saber como funciona por dentro uma TV, e de sentir como é ocupar este palco eletrônico, serviriam, na verdade, ao desejo narcísico de expressão da pós-modernidade, de que fala Lipovetsky (1983), ao tematizar que um de seus trunfos é a possibilidade de todos poderem ser expressar. Cada um, com aval das novas tecnologias, pode ser disk jockey, ter sua home page, ou, talvez, sua própria TV. Democratização sem precedentes, porém, a nosso ver, nem sempre traduzida em criação.

Nestas duas experiências em TV comunitária jovens da Baixada, usuários do sistema de saúde mental podem se ver, podem ser expressar. Forma narcísica de reconhecimento? Talvez. No entanto, há algo além do que apenas uma nova expressão da "fogueira das vaidades". A nosso ver, existe uma dimensão afirmativa nesta relação narcísica, ao se querer ver refletido, como uma espécie de expressão de dignidade, valorizando-se como capaz. Tal cuidado estético, mas, sobretudo ético, abre a possibilidade de criação de um outro campo de análise, seja sobre a loucura ou sobre a juventude na Baixada.

Ao se verem no vídeo essas comunidades se afirmam enquanto potência individual e coletiva. Eles se embelezam, ajeitam a postura, querem aparecer belos e atraentes, quem sabe até glamourizados, aos olhos dos outros, mas, principalmente, de si próprios. O vídeo-espelho utilizado pela TV Maxambomba e pela TV Pinel possibilita não o puro reflexo, mas um deslocamento espaço-temporal, pois o que se vê é o passado, um distanciamento com o próprio corpo, até mesmo ajudando a reconstruí-lo, numa ação coletiva, pois os vídeos são feitos e vistos em grupo.

Enquanto a TV de grande porte navega em direção à interatividade estas experiências em TV comunitária, ao concentrar-se no processo de criação, vem trabalhando em termos de circularidade. Ao contrário das grandes e médias emissoras de televisão, que têm sua produção setoriada e hierarquizada, o processo de criação destes vídeos comunitários é eminentemente coletivo e compartilhado. Apesar de definirem antecipadamente determinadas funções para cada membro do grupo, depois de uma reunião de pauta onde todos participam, o que se vê em todo o processo de criação do vídeo, é a circularidade de papéis entre os membros da equipe. Na TV Pinel o coordenador da equipe vira ator, o aluno/repórter da TV Maxambomba assume a direção. As funções se confundem no processo de criação, tornando explícita a dimensão polifônica na produção do conhecimento e da subjetividade, redimensionando a própria autoria.

A medida em que se apropriam dessa linguagem audiovisual, que entendem o processo de criação e produção de um vídeo eminentemente coletivo, passam também a ter um outro olhar sobre a "TV nossa de cada dia". Vejamos alguns depoimentos dos jovens da TV Maxambomba:

L- Aqui na TV comunitária todo mundo pensa, todo mundo tem o direito de opinar, dar suas idéias. Eu acho que em TV grande não tem isso. 
D- Mas deveria ter!

L- Acho que é... o câmera está ali para que? Não tem cérebro, quem manda é o diretor. Cada um com a sua função específica, mas sendo que tem sempre um cara atrás, mandando tudo. Então eles [são] assim. Eles querem passar alguém, eles querem proteger alguém? Não é possível, eles tem medo! O que um "sem terra" pode fazer contra uma emissora? Agora, vê se eles colocam 2 horas de um "sem terra" falando e 10 segundos de um político!? Eles podem ser vetados! Eu percebo isso logo. Me dá uma raiva....

\section{Na TV Pinel:}

E - Teve uma menina que veio fazer entrevista aqui. Aí a menina virou e começou a conversar comigo. Eu tive uma crise, fui internado. Ela pegou: "como é que é quando você tem crise? Eu só tive uma crise! Não, tudo bem. Mas como é que quando você tem crise?" Toda hora, insistiu que eu tinha mais de uma crise. E eu só tive uma crise!

Enquanto que a TV de massa visa predominantemente o sujeito consumidor, estas experiências em TV comunitária promovem o sujeito cidadão, que debate, que reivindica e que cria. E aí se instala a diferença...

\section{CONSIDERaÇões FINAIS}

Diante da falência da utopia, através do individualismo pós-moderno atravessado pelo consumo, as propostas dessas duas TVs comunitárias aqui apresentadas, expressam um valioso contraponto. Em um só movimento, suas práticas articulam-se no campo de subjetividade coletiva e evocam uma perspectiva política. Em tempos descrentes, elas não deixam de assumir um papel de caráter utópico: uma quer mudar a imagem da loucura, outra reivindica uma existência digna na Baixada, ambas querem o exercício pleno da existência. Para isso, elas se apropriam da linguagem midiática, com seus riscos de "sordidez", para ressignificá-la e expressar os seus desejos produtivos não atrelados ao consumo.

Se não há efetivamente, rupturas com a televisão de massa, há diferenças sensíveis, onde é possível constatar um aprofundamento da função cultural e pedagógica que the cabe. Justamente por poder ocupar um outro lugar enunciativo, onde não há obrigação de se fazer programas diários em ritmo industrial, ou compromisso com a venda de produtos ligados à grade de programas, nem com a "perfeição técnica asséptica" da TV de grande e médio porte, a TV comunitária pode ir além da informação, podendo capturar o inesperado, o inusitado do processo sem domesticá-lo.

Ao contrário da privatização da subjetividade, vista, por exemplo, no confinamento do espaço doméstico, no ato de assistir televisão, mesmo que traga o espaço público para dentro dos lares, estas experiências em TVs comunitárias visam a uma perspectiva de produção de subjetividade coletiva. Quer no processo 
de criação dos vídeos gestados em grupos com circularidade de funções, quer na exibição em espaços públicos, ruas, praças ou em auditórios, há sempre uma ação partilhada no ato de fazer / ver TV, onde os criadores das imagens/produtores de subjetividade também encontram e presentes.

\section{Notas}

${ }^{1}$ No Brasil, o movimento surge na conjuntura da pré-democratização do país, em fins dos anos 70, inspirado na trajetória do psiquiatra italiano Franco Basaglia. No início, a organização é protagonizada pelo Movimento dos Trabalhadores em Saúde Mental, com formulações teóricas balizando as intervenções na área. A partir da década de 80, a luta é expandida, surgindo o Movimento Nacional da Luta Antimanicomial, com participação não só de profíssionais de saúde mental, mas de usuários, familiares e de outros segmentos da sociedade civil. O Projeto de Lei Paulo Delgado decorre desse movimento e regulamenta a internação psiquiátrica compulsória, propondo a substituição gradativa do manicômio por outras formas de tratamento, como o hospital/dia, o ambulatório, os centros de convivência, lares protegidos e leitos psiquiátricos em hospitais gerais. Seguindo as diretrizes da Declaração de Caracas (conferência realizada em 1990 sobre a Reestruturação da Atenção Psiquiátrica na América Latina) e da II Conferência Nacional em Saúde Mental, realizada em Brasília em 1992, o Ministério da Saúde vem reduzindo o número do internações psiquiátricas e implantando novos serviços, como os que ocorrem no IPP (Instituto Philippe Pinel). Neste, a internação se restringe apenas ao período de crise do usuário, priorizando o tratamento no hospital/dia em diversos setores, como o atendimento no ambulatório.

${ }^{2}$ Para compreensão do conceito de subjetividade aqui proposto v. Guattari: As três Ecologias (1990),

Caosmose, Um Novo Paradigma Estético (1992); e Lins (org) (1997) Cultura e Subjetividade, e Miranda (2000) Subjetividade: a (des)construção de um conceito.

${ }^{3}$ Bakhtin $(1995,2000)$, em sua teoria sobre a linguagem, adota uma perspectiva dialógica, em que o mundo é construído no diálogo que remonta a inúmeras vozes, e indica-nos a eminência de uma realidade predominantemente polifônica. $\mathrm{O}$ enunciado proferido por um sujeito, além de ter que ser relacionado com seu contexto para poder ser compreendido, não é, em absoluto, uma prática individual, visto que sua fala representa um entrecruzamento de vozes, de diversos discursos que lhes são anteriores. Assim, ao lado do caráter social da subjetividade, inscreve-se com Bakhtin, a mesma perspectiva em relação à linguagem.

${ }^{4}$ Referência aos slogans utilizados pela TV Maxambomba e pela TV Pinel.

${ }^{5}$ O Projeto Repórter de Bairro foi desenvolvido entre 1994 e 1996. Neste projeto moradores das diversas regiões de Nova Iguaçu se integravam à equipe da TV Maxambomba para a realização de pauta, produção e exibição. Aos poucos, porém, com o amadurecimento do projeto e conforme a demanda de alguns membros da localidade, a equipe da TV começou a inserir oficinas de áudio, câmera, direção e edição, para que, por meio de apropriação da linguagem do vídeo pela população, se pudesse, efetivamente, dominar a tecnologia em que esta linguagem encontra-se inserida.

${ }^{6} \mathrm{~A}$ TVE é pública e funciona como canal aberto. O Canal Futura pertence às organizações Globo em parceria com o Governo Federal e é transmitida por antena parabólica e TV a cabo. A TV Facha é universitária, ligada as Faculdades Hélio Alonso, (Rio de Janeiro).

7 Metodologia frequentemente utilizada na exibição de rua: após a exibição, os temas relacionados aos vídeos comunitários são debatidos pela comunidade e transmitidos ao vivo, no local. Os jovens alunos conduzem o processo e a comunidade além de discutir acerca do tema do vídeo exibido, também protagoniza uma experiência com a imagem, a medida em que se vê enquanto fala. Não raramente a auto-imagem torna-se tema de discussão.

${ }^{8}$ Embora as duas TVs tenham princípios metodológicos semelhantes, suas dinâmicas são diferentes em termo de vídeo-processo. O projeto de "Capacitação de Jovens em Produção de Vídeo" da TV Maxambomba valoriza o cunho educativo, pela crença na eficácia pedagógica através do vídeo, interferindo na condução de sua dinâmica, em que cada etapa do processo tem um espaço de discussão e manuseio do aparato técnico por parte dos jovens. Na TV Pinel a dinâmica encontrase mais voltada para a prática. A explicação acerca da linguagem do vídeo, o roteiro, o planoseqüência, a edição surgem no ato do próprio fazer vídeo com a população de usuários, porém, é a equipe técnica também composta de alguns usuários, que manipulam o aparato tecnológico: câmera, áudio, mesa de edição. 


\section{REFERÊNCIAS}

AMORIM, M. O pesquisador e seu outro: Bakhtin nas Ciências Humanas. São Paulo: Musa, 2001.

BAKHTIN, M.

Estética da criação verbal. 3. ed. São Paulo: Martins Fontes, 2000. 1995. Marxismo e filosofia da linguagem. 7. ed. São Paulo: Hucitec,

BAUDRILLARD, J. Sociedade de consumo. Rio de Janeiro: Elfos, 1995. BUCCI, E. Ética versus loucura. Folha de São Paulo, São Paulo, p. 2, 18 ago. 2002.

DELEUZE, G.; GUATTARI, F. $O$ anti-édipo: capitalismo e esquizofrenia. Lisboa: Assírio e Alvim, 1972.

GUATTARI, F. As três ecologias. Campinas, SP: Papirus, 1990.

Caosmose: um novo paradigma estético. Rio de Janeiro: Ed.34, 1992

GUATTARI, F.; ROLNIK, S. Micropolitica: cartografias do desejo. Petrópolis: Vozes, 1986.

LINS, D. (Org.). Cultura e subjetividade: saberes nômades. Rio de Janeiro: Papirus, 1997.

LIPOVETSKY, G. A era do vazio: ensaio sobre o individualismo contemporâneo. Lisboa: Relógio D’Água, 1983.

. Criadores de imagens, produtores de subjetividade: a experiência da TV Pinel e da TV Maxambomba. 2002. Tese (Doutorado) - Pontifícia Universidade Católica, Rio de Janeiro, 2002.

Recebido em: Julho/2006

Aceito em: Setembro $/ 2006$ 
